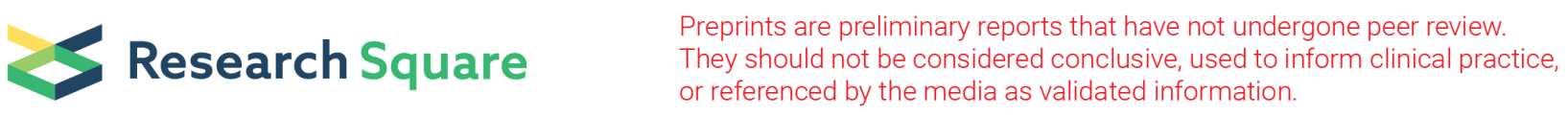

\title{
Analysis of COVID-19 based on SEIR epidemic models in a multi-patch environment
}

\section{Lan Meng}

Chongqing University of Posts and Telecommunications

Wei Zhu ( $\square$ zhuwei@cqupt.edu.cn )

Chongqing University of Posts and Telecommunications https://orcid.org/0000-0003-1120-9750

\section{Research Article}

Keywords: COVID-19, n-patch SEIR epidemic model, Basic reproduction number, Quarantine strategy, Migration rate

Posted Date: April 12th, 2021

DOl: https://doi.org/10.21203/rs.3.rs-306960/v1

License: (1) This work is licensed under a Creative Commons Attribution 4.0 International License. Read Full License 


\section{Abstract}

In this paper, an n-patch SEIR epidemic model for the coronavirus disease 2019 (COVID-19) is presented. It is shown that there is unique disease-free equilibrium for this model. Then, the dynamic behavior is studied by the basic reproduction number. Some numerical simulations with three patches are given to validate the effectiveness of the theoretical results. The influence of quarantined rate and population migration rate on the basic reproduction number is also discussed by simulation.

\section{Full Text}

This preprint is available for download as a PDF.

\section{Figures}

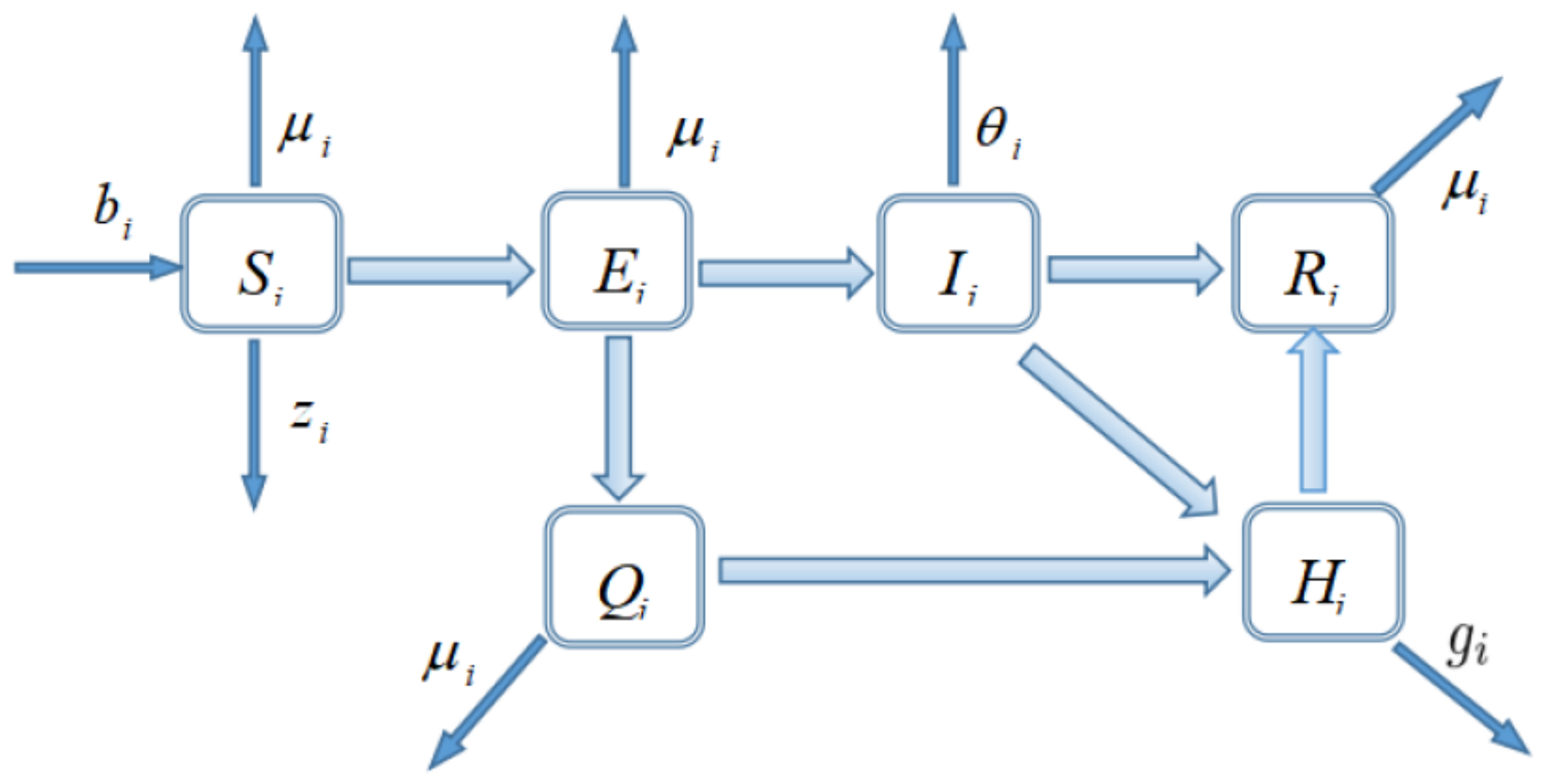

Figure 1

The disease transmission in each patch. 


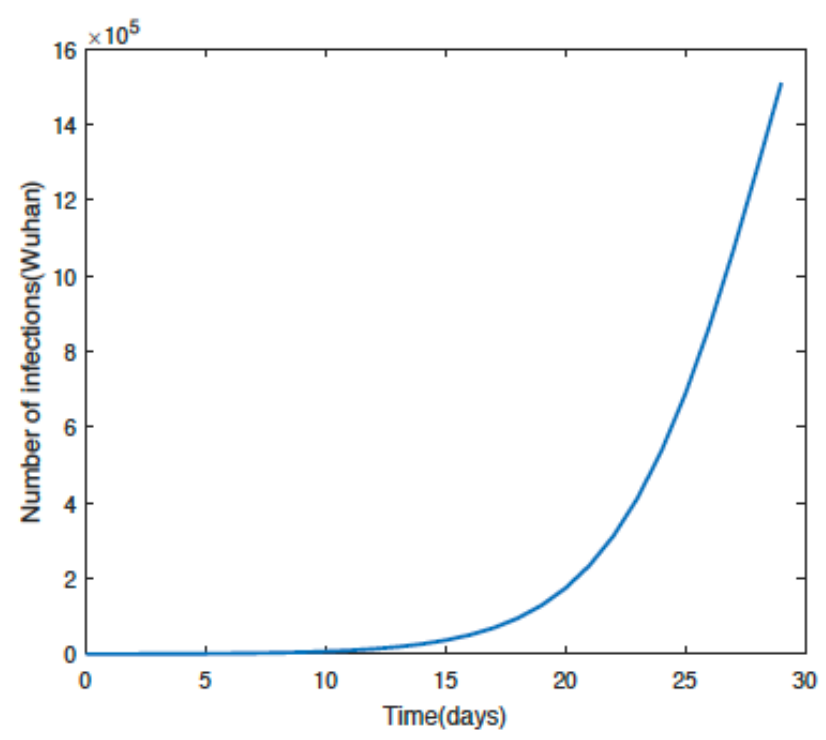

(a)

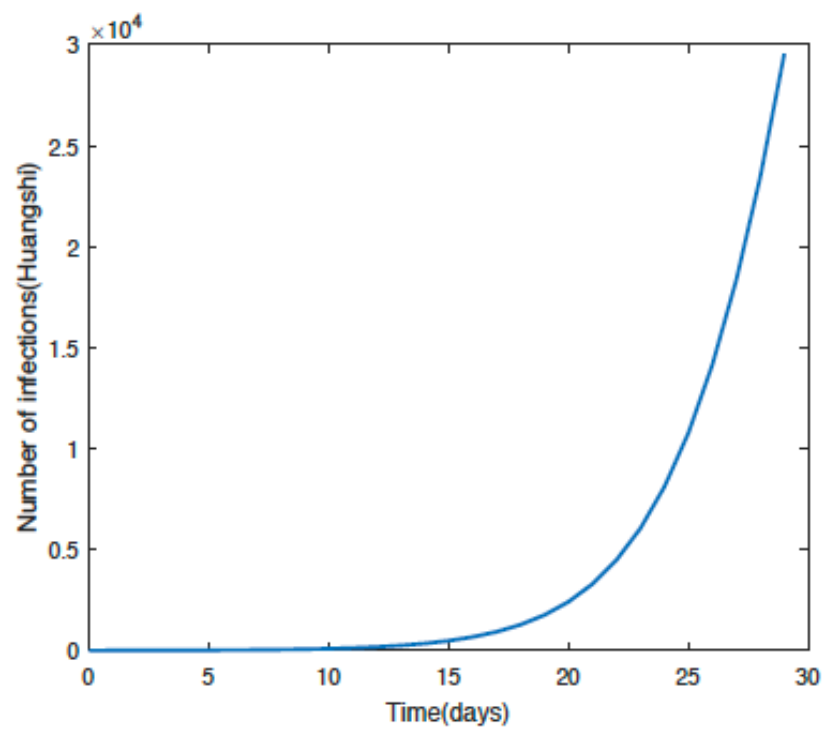

(c)

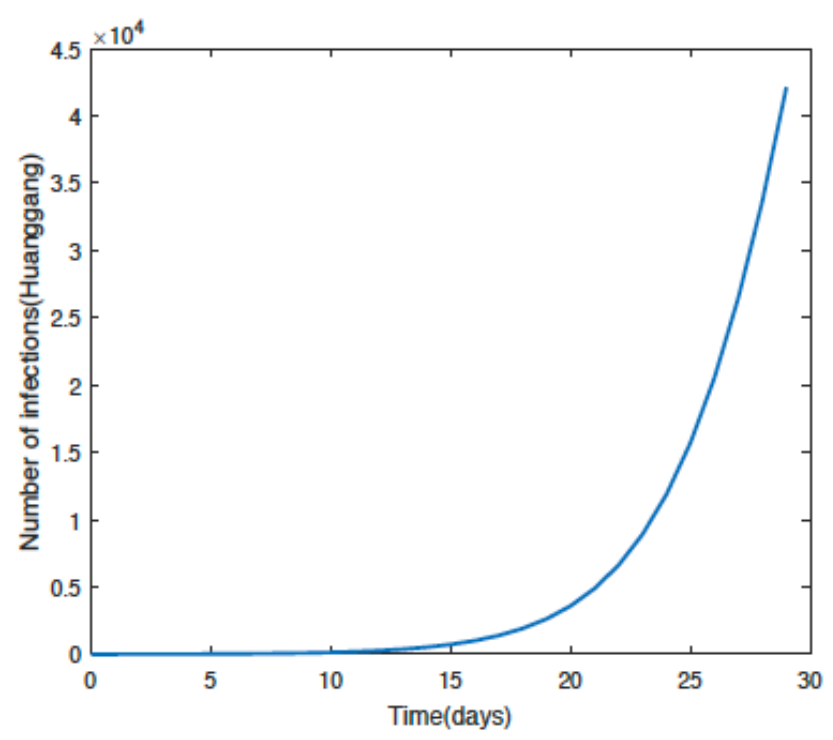

(b)

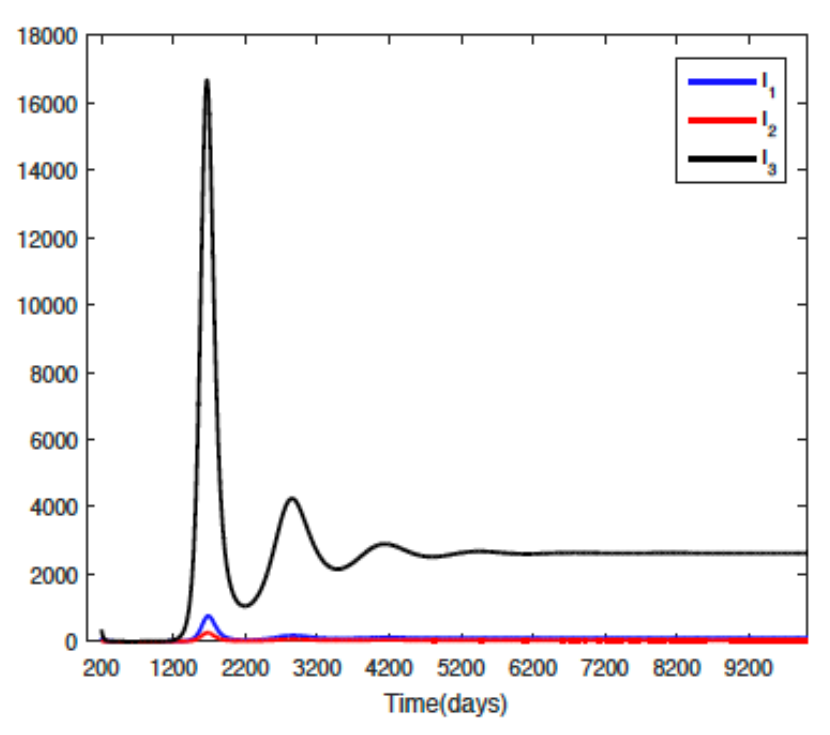

(d)

\section{Figure 2}

Time evolution of individuals when $P=P 0, q i=0, z i=0, i=1 ; 2 ; 3$. Case II: Migration of people is restricted and quarantine strategy is taken. 


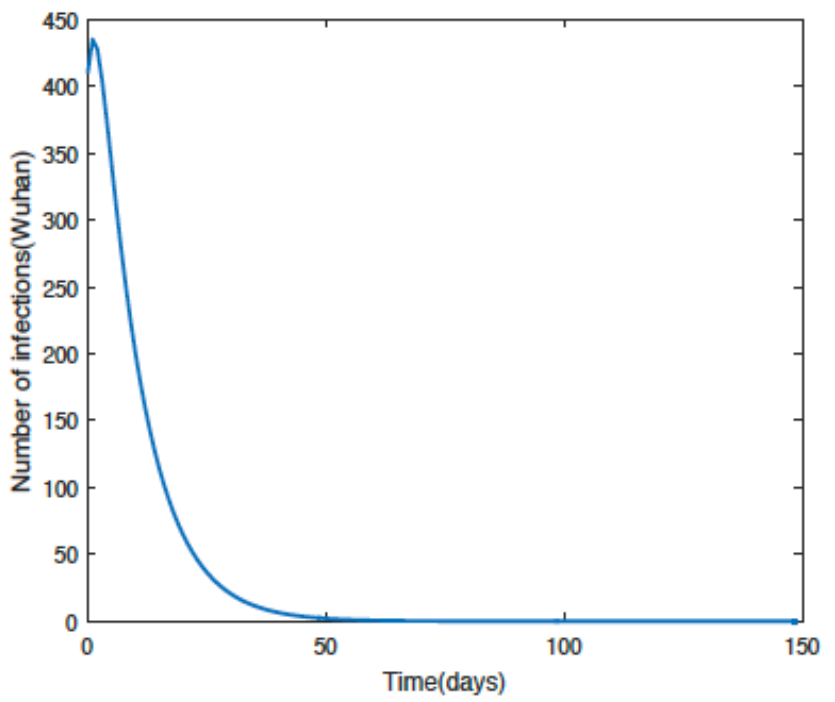

(a)

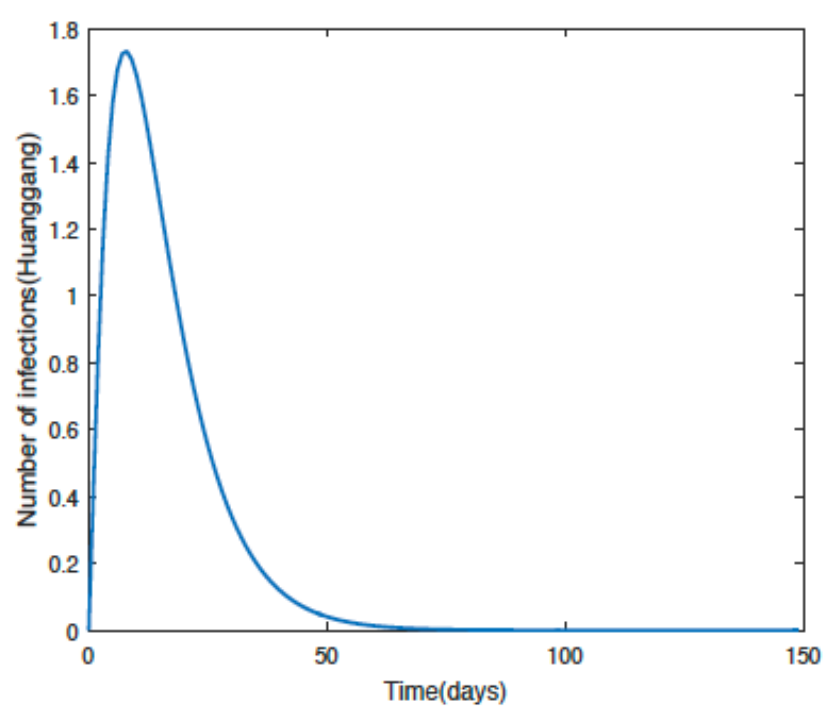

(c)

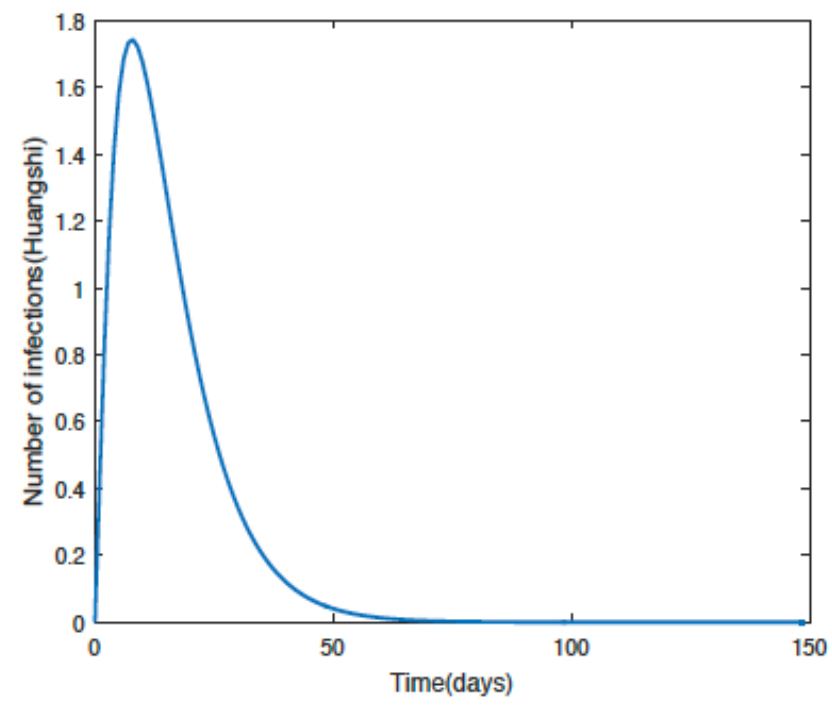

(b)

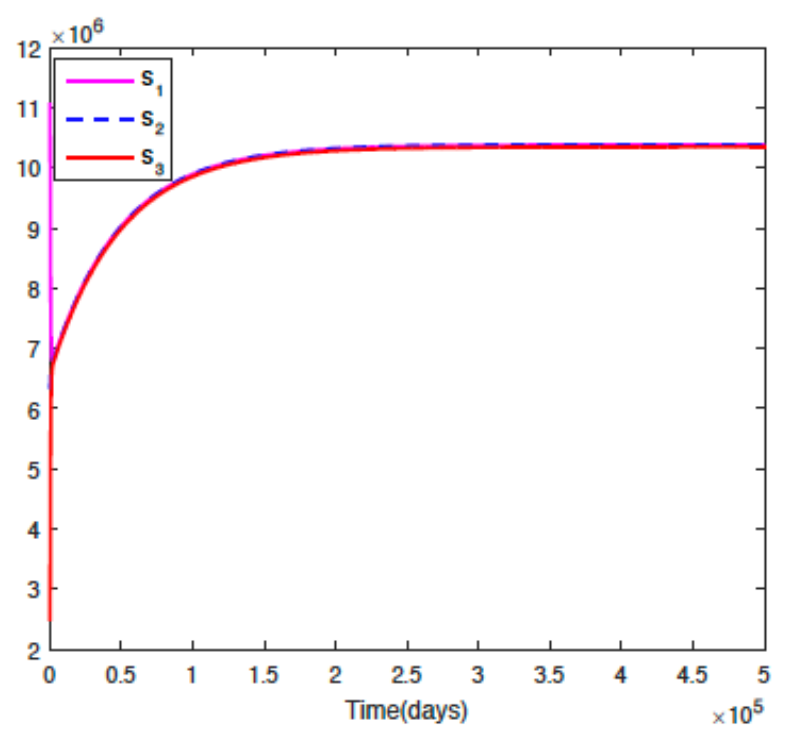

(d)

\section{Figure 3}

Time evolution of individuals when $P=0, q i=0: 5, z i=0: 3, i=1 ; 2 ; 3$. 


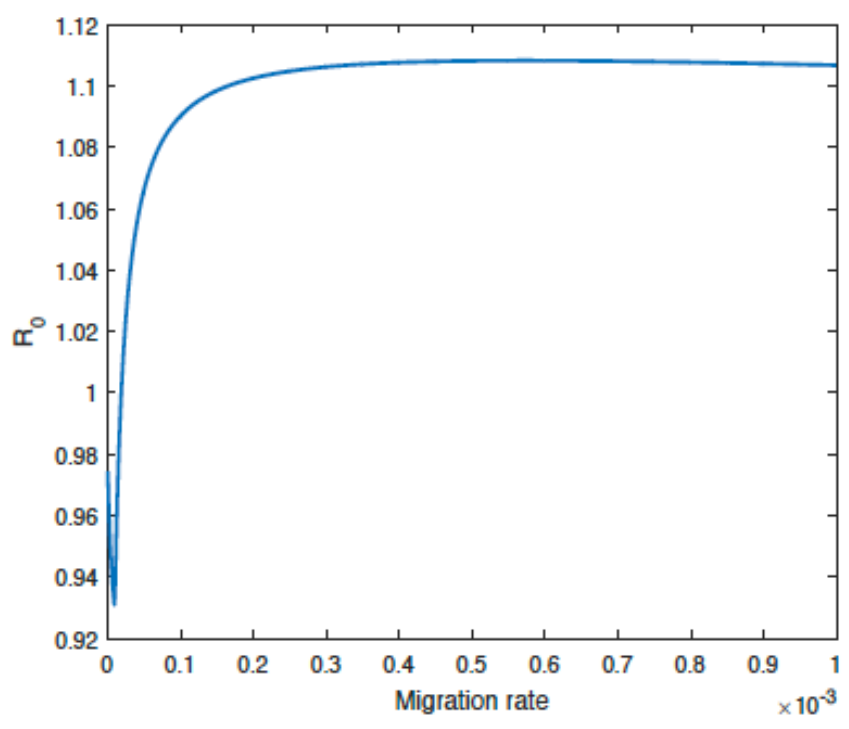

(a) $p_{i j} \in[0,0.0005]$

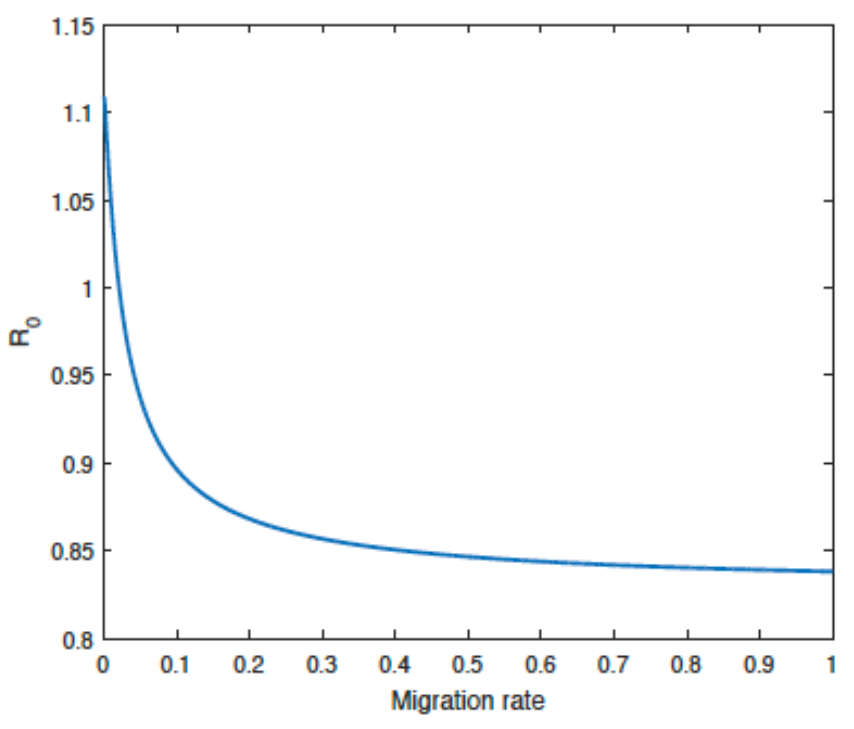

(b) $p_{i j} \in(0.0005,1]$

\section{Figure 4}

The effect of migration rate on $\mathrm{R} 0$. 


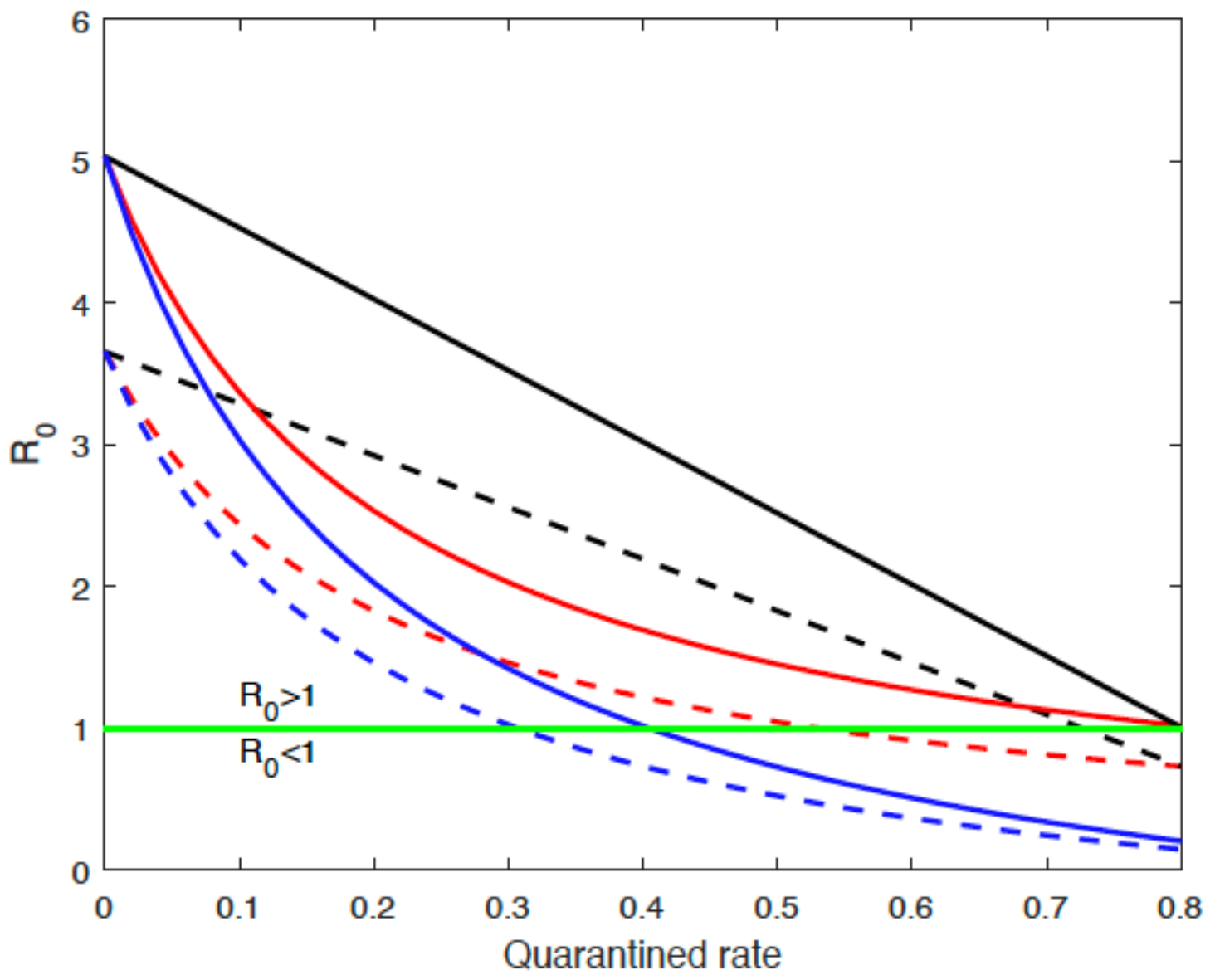

Figure 5

The effect of quarantined rate on $\mathrm{R} 0$. 